\title{
Robotic assisted gait as a tool for rehabilitation of individuals with spinal cord injury: a systematic review
}

\author{
Ledycnarf J. Holanda ${ }^{1 *}$, Patrícia M. M. Silva', Thiago C. Amorim', Matheus O. Lacerda², Camila R. Simão 2,3 \\ and Edgard Morya ${ }^{1,3}$
}

\begin{abstract}
Background: Spinal cord injury (SCl) is characterized by a total or partial deficit of sensory and motor pathways. Impairments of this injury compromise muscle recruitment and motor planning, thus reducing functional capacity. SCl patients commonly present psychological, intestinal, urinary, osteomioarticular, tegumentary, cardiorespiratory and neural alterations that aggravate in chronic phase. One of the neurorehabilitation goals is the restoration of these abilities by favoring improvement in the quality of life and functional independence. Current literature highlights several benefits of robotic gait therapies in $\mathrm{SCl}$ individuals.

Objectives: The purpose of this study was to compare the robotic gait devices, and systematize the scientific evidences of these devices as a tool for rehabilitation of SCI individuals.

Methods: A systematic review was carried out in which relevant articles were identified by searching the following databases: Cochrane Library, PubMed, PEDro and Capes Periodic. Two authors selected the articles which used a robotic device for rehabilitation of spinal cord injury.

Results: Databases search found 2941 articles, 39 articles were included due to meet the inclusion criteria. The robotic devices presented distinct features, with increasing application in the last years. Studies have shown promising results regarding the reduction of pain perception and spasticity level; alteration of the proprioceptive capacity, sensitivity to temperature, vibration, pressure, reflex behavior, electrical activity at muscular and cortical level, classification of the injury level; increase in walking speed, step length and distance traveled; improvements in sitting posture, intestinal, cardiorespiratory, metabolic, tegmental and psychological functions.
\end{abstract}

Conclusions: This systematic review shows a significant progress encompassing robotic devices as an innovative and effective therapy for the rehabilitation of individuals with $\mathrm{SCl}$.

Keywords: Robotic assisted gait, Rehabilitation, Robotic devices, Spinal cord injury

\section{Background}

In the world, around 250 to 500 thousands people suffer spinal cord injury (SCI) every year. SCI is caused by a damage in neural structures of the spinal cord, such as medulla, medullary cone and/or cauda equina. Tissue lesions are mostly due to mechanical impact, laceration, compression, transection, infection or spinal cord

\footnotetext{
* Correspondence: fisioledyholanda@gmail.com

${ }^{1}$ Neuroengineering Program, Edmond and Lily Safra International Neuroscience Institute, Santos Dumont Institute, Rodovia RN 160, Km 03, 3001 Distrito Jundiaí, Macaíba 59280-000, Brazil

Full list of author information is available at the end of the article
}

degeneration. SCI is classified in two categories: incomplete or complete. The first is determined by motor and sensory partial preservation and reduced electromyographic (EMG) signal below the injured level, whereas the second is determined by a complete loss of sensorimotor activity and EMG signal below the level of lesion $[1,2]$. The sensorial input and motor output are reduced or absent in SCI patients. Thus, muscular recruitment and motor planning become compromised, which leads to a reduced functionality [3, 4]. Chronic SCI patients are predisposed to secondary complications such as psychological, bowel, urinary, musculoskeletal, neuronal, 
cutaneous and cardiorespiratory $[1,4,5]$. Therefore, one of the challenges in neurorehabilitation to restore functional independence and quality of life is the recovery of planning and executing the movement again $[2,6]$. Locomotor functional training is one of the rehabilitation aims in SCI patients. However, body weight sup- port (BWS) over a treadmill associated with manual assistance leads to therapist physical exhaustion. Since the exponential technological evolution, the idea of improving rehabilitation, and orthotic devices considering anatomic axes of lower limb have been developed. This may reduce professional physical exhaustion and bring new outcomes to rehabilitation [6, 7]. As a result, many studies that investigate the therapeutic effects of these orthotic devices have been published recently. Several researchers identified that robotic assisted gait training (RAGT) in SCI patients improved the cardiorespiratory, urinary, musculoskeletal, neuronal and somatosensory system, due to body compensation and neural plasticity [8-13]. Therefore, this review aims to compare features, and offer additional information for robotic devices application, and systematize scientific evidences from researches which used these devices as a tool for rehabilitation of SCI individuals. It is expected that this knowledge compilation may support further therapies, and researches to improve organic function and quality of life of SCI patients.

\section{Methods}

\section{Literature search}

The following databases were searched between February 2016 and October 2017: Cochrane Library, PubMed, PEDro and Periódico Capes and the manuscript was drafted from July 2016 to October 2017. To guarantee the most accurate keywords, it was conducted a search in Medical Subject Headings (MeSH) with "spinal cord injury", "tetraplegic", "paraplegic", "lower limbs paralysis" and "lower extremity paralysis" associated with "body weight support", "assisted gait", "driven gait ortho- sis", "orthotic gait training", "gait training", "robotic gait", "exoskeleton", "treadmill rehabilitation", "walking", "gait", "locomotion", "overground walking", "robotic assisted gait", "robotic assisted gait training", "treadmill", "physiotherapy", "physical therapy", "locomotion therapy", "robotic assisted gait therapy", "locomotor treatment".

\section{Selection of trials}

Two authors selected the relevant articles, according to the following pre-established criteria. Relevant researches were identified and included only publication in English, Portuguese and Spanish. Exclusion criteria: reviews, duplicates and not full article. All papers which used a robotic device for spinal cord injury rehabilitation were included independent of the publication year up to 2017.

\section{Data synthesis and results}

The literature search undertaken yielded 2941 records, of which initially, the titles and abstracts were read and excluded the duplicate articles. In addition, review articles and not full text were excluded, resulting in 240 articles. Then, the articles that did not use robotic device were excluded. Thus, after careful analysis, 39 articles were included in the full-text review. Figure 1 illustrates the PRISMA flowchart of the results from the literature search performed by two authors followed guidelines for scale's application as shown.

Table 1 (see Additional file 1: Table 1) shows the robotic devices and their features e.g. treadmill, BWS, guidance force (GF), degrees of freedom (DOFs), maximum pa- tient weight and torso and upper limb muscle strength, and additional information available in the reviewed articles. All devices used in the reviewed articles are pre- sented in Figure 2 with exception of the Welwalk WW-1000 (K), which has not been published yet with SCI patient (see Figure: Figure 2). The Figure 3 (see Figure: Figure 3) schematics the increasing use of robotic devices over the years in rela- tion to the purpose of their application, highlighting the benefits of sensorimotor, cardiorespiratory, metabolic, reflex behavior; kinetic and kinematic parameters.

Further, the tables from two to five contain data from the articles: study design, patients' demography, rehabilitation, outcome measures and results of each article inserted in this review listed according to the publication year in ascending order. Moreover, the tables were split into groups according to outcome measure: cardiorespiratory and metabolic parameters (Additional file 2: Table S2), parameters of reflex behavior (Additional file 3: Table S3), kinetic and kinematic parameters (Additional file 4: Table S4), and sensory and motors parameters (Additional file 5: Table S5) (see Additional file 2: Table S2, Additional file 3: Table S3, Additional file 4: Table S4, Additional file 5: Table S5, respectively).

\section{Discussion and conclusions}

The primary goal of this study was to conduct a systematic review of scientific evidence related to the use and features of robotic devices in the rehabilitation of patients with SCI. From this review, it is possible to base and guide news prospects for rehabilitation and research, in view of the numerous benefits that this type of therapy is able to provide.

Robotic devices are technologies in constant evolution, e.g. recently was released the Welwalk WW-1000 (L), which allows pelvis, hip and knee motion for gait training with BWS and treadmill [14] (see Fig. 2). The nonstop innovation may offer a paradigm change in the treatment of individuals with a neurological disorder [15]. The exponential technological development lined 


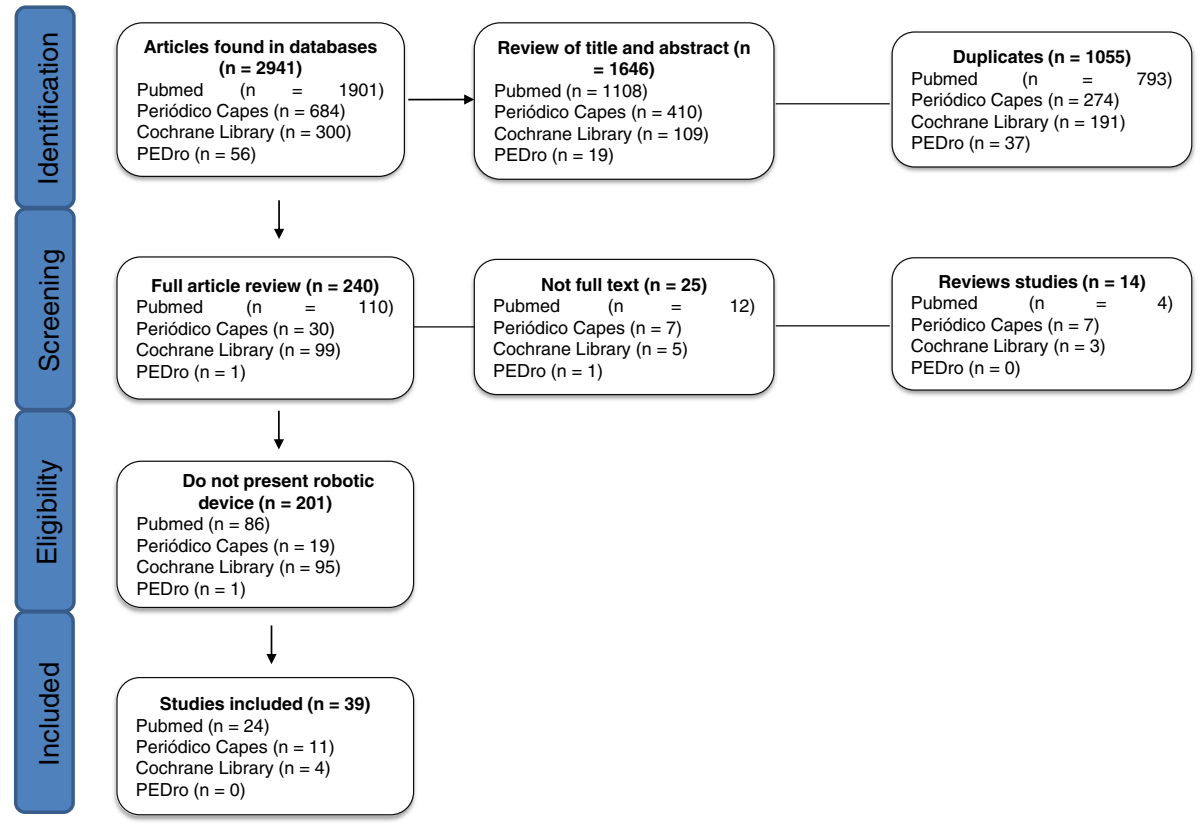

Fig. 1 Prisma flowchart of the results from the literature search

up with rehabilitation device research is demanding new skills for the rehabilitation professional of the future.

The studies included in these review cited features in relation to the devices, which should be considered to select the appropriate tool for each individual due to the peculiarity of the requirements for its use. In addition, the devices cited may be ap- plied in indoor or outdoor environments, considering different DOFs, levels of GF, physical efforts demand and higher energy expenditure. The LokomatPRO (plus FreeD module) and LOPES are not portable and have as main specification indoor use, BWS and treadmill [16-19].

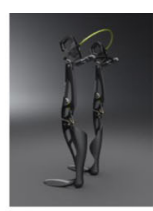

ARGO (A) (COROFLOT, 2015)

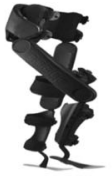

Indego $(\mathrm{E})$ (Hartigan et al., 2015)

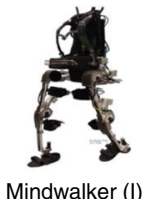

Mindwalker (I)

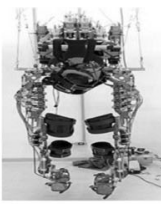

Brain-controlled robotic exoskeleton (EXO) (B)

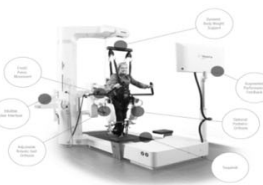

Lokomat FreeD Module (F) Pelvic (Hocoma, 2017)
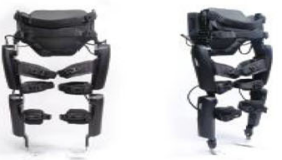

ReWalk (J) (CADTH Evidence Driven, 2015)

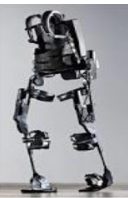

EKSO (C) (Kozlowski, Bryce, Djikers, 2015)

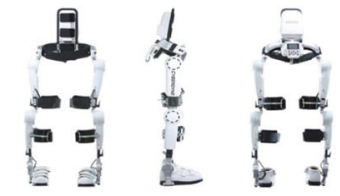

HAL (D)

(Walk Again Center, 2015)

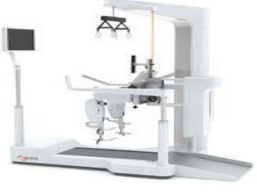

LokomatPRO (without FreeD module) (G) (BR Biomedicals Pvt. Ltd., 2015)

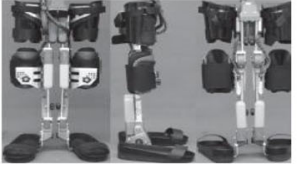

WPAL (K) (Tanabe, Hirano, Saitoh, 2013)

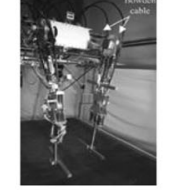

LOPES (H) (Fleerkotte et al., 2014)

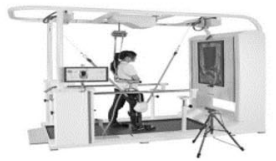

Welwalk WW-1000 (L) (MEDGADGET, 2017)

Fig. 2 Robotic devices used for rehabilitation of individuals with SCI 
Whereas the ARGO, EKSO, Indego, Re- Walk and WPAL can be used either in outdoor and indoor environments. However, these equipment require high upper limb load, trunk muscles strength and excessive energy expenditure due to gait assistance devices such as crutches or walker to en- sure stability and safety of the user [9, 20-28]. Besides possessing these characteristics, the HAL and Mindwalker present a controlled activity by bioelectrical signals detected through surface EMG electrodes measured in extensor and flexor muscles of the hip and knee $[12,15,18,25,26]$. The EXO does not require neither muscles strength of upper limbs and trunk, nor postural control to execute gait and it is flexible to adjust in a variety of different leg lengths [11]. Thus, it seems reasonable that robotic gait technology will merge several features to allow innovative rehabilitation.

Moreover, this review showed that this type of intervention is able to provide benefits that exceed improvement of sensorimotor functions of this population. Figure 3 highlights the applications of robotic devices for improving sensorimotor, cardiorespiratory and metabolic parameters until the approaches to altered reflex behavior, kinetic and kinematic parameters (see Fig. 3). Among these changes are included, improvements in activity performance, postural control, urinary and bowel functions, which are directly related to the improvements of psychological characteristics and life quality.

The rehabilitation protocol based on specific task enhances neuroplasticity in individuals with SCI. In this case, it is important to consider the rehabilitation parameters used, which should be related to the injury level, classification, and the secondary changes. During any training session, the BWS level was selected as the minimum amount of assistance that would not create excessive knee flexion during posture or drag during the swing that was diminished by $5 \%$ of BWS. In the inserted studies, initial BWS was averaged $60 \%$ and lasted $45-50 \%$. The weekly frequency predominance was 2-3 times per week with low to moderate intensity. The initial treadmill speed varied between 0.22 and $0.56 \mathrm{~m} / \mathrm{s}$ and, increased by $0.02 \mathrm{~m} / \mathrm{s}$. Some studies have graded treadmill speed, GF and BWS according to $\mathrm{HR}, \mathrm{VO}_{2}$ and MET of each individual.

Numerous studies revealed changes below the level of injury with multiple variables observed in the course of its protocol corroborating with results that indicate reduced pain perception and spasticity level $[29,30]$. Likewise, it was observed changes in the proprioceptive ability, sensitivity to temperature, vibration, pressure, behavior reflex, electrical activity of muscle and cortical level $[10,11,31-44]$ and changes in the level of injury classification. Further, recovery of sensorimotor function; increased stability and strength of muscles thoracic and lumbar region [20]; functional improvements in skills in sitting posture and gait, in the bowel and urinary function, cutaneous and psychological. Therefore, positively impacting the performance of their routine activities, making these individuals with higher level of functional independence [11].

One study [45] suggests that the RAGT associated with anabolic medicine does not promote alterations in bone mineral density (BMD) index, although another study [11] found divergent results revealing that half of the participants showed no change while the other half obtained a small evolution without relation to the improvement of neurological aspect.

Rehabilitation improvements of an individual with SCI involves cardiorespiratory fitness, which is important in improving the quality of life as well as contributing to a better performance in routine activities. It was observed that improvements in this aspect provide a better performance of gait related to increasing walking speed, stride length, distance walked $[9,24,46-49]$, related to the reduction of $\mathrm{HR}$,

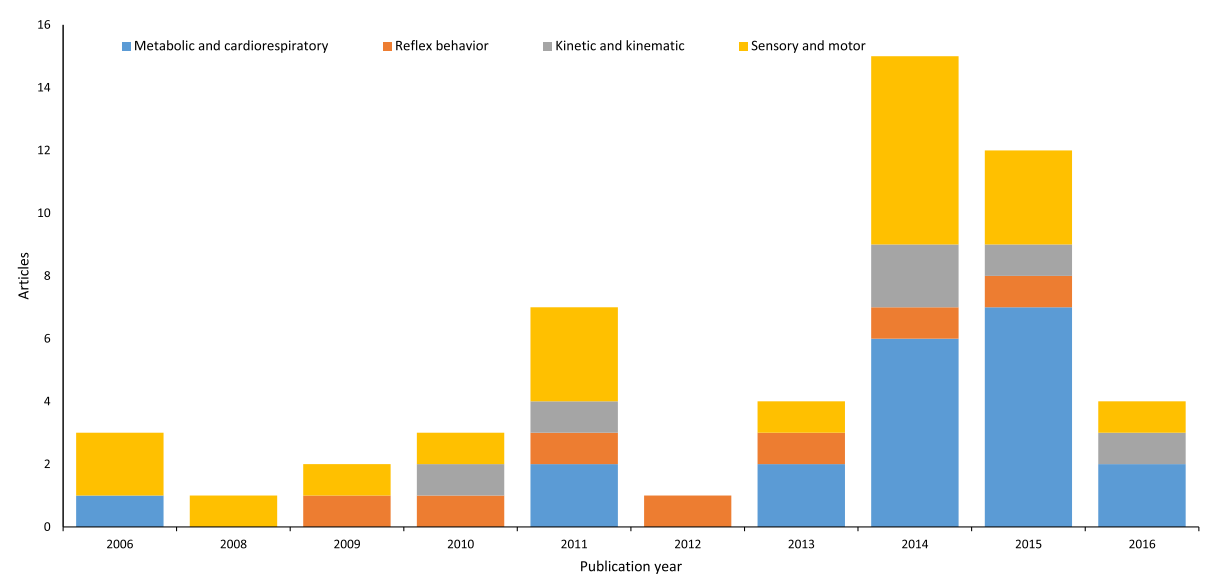

Fig. 3 Robotic devices applications in the last years 
$\mathrm{BF}, \mathrm{MET}$ and $\mathrm{VO}_{2}$. Studies $[21,31,50,51]$ found a $\mathrm{VO}_{2}$ and $\mathrm{HR}$ variation when compared these parameters in sitting and orthostatic positions. Further, it was observed that the higher GF applied to assist walking, the lower HR and MET, suggesting that the RAGT interferes in the increase of energy expenditure, this is capable to provide metabolic and cardiorespiratory benefits.

In conclusion, studies have been able to identify benefits promoted by the robotic gait devices in SCI treatments. It is expected in near future that devices should be used not only during therapy but also in daily living activities. None the less, the devices should be hybrid putting together the current SCI individuals abilities and supporting them where and when their skills lack, including feedbacks mechanisms to improve the user benefit from the device. It corroborates to a more individual centered therapy, based on their specifics needs. Scientific and technological evidence shows significant progress encompassing RAGT as an innovative and effective therapy for the rehabilitation of individuals with $\mathrm{SCI}$, achieving promising results from improvements in cardiorespiratory, musculoskeletal, intestinal, urinary, neural, somatosensory and psychological functions. One of the important features of this type of treatment is to be a specific therapy based on motor learning improvements, in which promotes neuroplasticity and reduce secondary injury complications.

\section{Additional files}

Additional file 1: Table S1. Description of the robotic device(s) used as a tool for rehabilitation of individuals with SCI. (PDF $157 \mathrm{~kb}$ )

Additional file 2: Table S2. Studies that presented metabolic and cardiorespiratory parameters as outcome measures in individuals with SCl. (PDF 257 kb)

Additional file 3: Table S3. Studies that presented altered reflex behavior parameters as outcome measures in individuals with SCl. (PDF 345 kb)

Additional file 4: Table S4. Studies that presented kinetic and kinematic parameters as outcome measures in individuals with SCl. (PDF 197 kb)

Additional file 5: Table S5. Studies that presented sensory and motors parameters as outcome measures in individuals with SCl. (PDF 273 kb)

\footnotetext{
Abbreviations

10MWT: 10-meter walk test; 2MWT: 2-minute walk test; $6 \mathrm{MWT}$ : 6 min walk test; ABC: Activities-specific balance confidence; AH: Abductor hallucis; AIS: American Spinal Injury Association impairment scale; ARGO: Advanced reciprocating gait orthosis; $\mathrm{AROM}$ : Active range of motion; $\mathrm{BDI}$ : Beck depression inventory; BF: Breathing frequency; BFM: Biceps femoris; BMD: Bone mineral density; BWS: Body weight support; CF: Crutch force; CG: Control group; COPM: Canadian occupational performance measure; DELTa: Anterior deltoid; DELTp: Posterior deltoid; DF: Dorsi-flexors; DGO: Driven gait orthosis; DOFs: Degrees of freedom; DXA: Dual-energy x-ray absorptiometry; EAW: Exoskeletal - assisted walking; ECU: Extensor carpi ulnaris; EEG: Electroencephalogram; EG: Experimental group; EMG: Electromyographic; EXO: FAC: Functional ambulation category; FCU: Flexor carpi ulnaris; FES-1: Falls efficacy scale; FET: Figure eight scale; FIM: Functional independence measure; FSR: Force-sensitive resistors; GF: Guidance force; GMM: Growth mixture modeling; GRC: Gracilis; GTX: Graded exercise test; HAL: Hybrid assistive limb; HR: Heart rate;
}

HS: Healthy subject; IPAQ: Impact on participation and autonomy questionnaire; LEMS: Lower extremity motor score; LH: Lateral hamstrings; LOA: Level of assistance; LSQ: Life satisfaction questionnaire;

LTSO: Thoracolumbosacral orthosis; MCF: Mean crutch force; MeSH: Medical Subject Headings; MET: Metabolic equivalents; MG: Medial gastrocnemius; $\mathrm{MH}$ : Medial hamstrings; MVC: Maximal voluntary contraction; P1NP: Intact aminoterminal propeptide of type I procollagen; PCF: Peak crutch force; PCl: Physiological cost index; PF: Plantar-flexion; PL: Peroneus longus; ppSEP: Paired pulse somatosensory evoked potentials; PROM: Passive range of motion; PTH: Parathyroid hormone; RAGT: Robotic assisted gait training; RF: Rectus femoris; ROM: Range of motion; RPE: Rate of perceived exertion; SCI: Spinal cord injury; SCI-FAP: Spinal cord injury-functional ambulation profile; SCIM: Spinal cord independence measure; SHO: Sides of the acromium; SOL: Soleus; $\mathrm{SpO}_{2}$ : Saturation of peripheral oxygen; SR: Spinal reflex; ST: Semitendinosus; TA: Tibialis anterior; TLSO: Thoracolumbosacral orthosis; TUGT: Timed up and go test; UEMS: Upper extremity motor score; VAS: Visual analog scale; VE: Pulmonary ventilation; VEL: Hip angular velocity; VL: Vastus lateralis; VM: Vastus medialis; $\mathrm{VO}_{2}$ peak: Peak cardiorespiratory capacity; $\mathrm{VO}_{2}$ : Oxygen uptake; VP: Velocity peak; WISCI II: Walking index for spinal cord injury II; WPAL: Wearable power-assist locomotor

\section{Acknowledgements}

The authors would like to thank Santos Dumont Institute (ISD), the Brazilian Ministry of Education (MEC) for their assistance during the research.

\section{Authors' contributions}

$\mathrm{LJH}$ reviewed the technical and clinical literature, and drafted the manuscript. MOL reviewed the technical and clinical literature and drafted the manuscript. TCO, PMMS, CRS and EM drafted the manuscript. All authors have read and approved the final manuscript.

\section{Competing interests}

The authors declare that they have no competing interests.

\section{Publisher's Note}

Springer Nature remains neutral with regard to jurisdictional claims in published maps and institutional affiliations.

\section{Author details}

${ }^{1}$ Neuroengineering Program, Edmond and Lily Safra International Neuroscience Institute, Santos Dumont Institute, Rodovia RN 160, Km 03, 3001 Distrito Jundiaí, Macaíba 59280-000, Brazil. Federal University of Rio Grande do Norte, Av. Sen. Salgado Filho Lagoa Nova, Natal 59078-970, Brazil. ${ }^{3}$ Anita Garibaldi Center of Education and Research in Health, Santos Dumont Institute, Rodovia RN 160, Km 02, 2010 Distrito Jundiaí, Macaíba 59280-970, Brazil.

Received: 7 June 2017 Accepted: 23 November 2017

Published online: 04 December 2017

\section{References}

1. WHO: WHO | Spinal cord injury (2016). http://www.who.int/mediacentre/ factsheets/fs384/en/ Accessed 2016-09-12.

2. Nas K, Yazmalar L, Sah V, Aydın A, Öneş K. Rehabilitation of spinal cord injuries. World J Orthopedics. 2015;6(1):8-16. https://doi.org/10.5312/wjo.v6.i1.8.

3. Frood RT. The use of treadmill training to recover locomotor ability in patients with spinal cord injury. Bioscience Horizons. 2011;4(1):108-17. https://doi.org/10.1093/biohorizons/hzr003.

4. Van Hedel HJA, Dietz V. Rehabilitation of locomotion after spinal cord injury. Restor Neurol Neurosci. 2010;28(1):123-34. https://doi.org/10.3233/RNN2010-0508.

5. Louie DR, Eng JJ, Lam T. Gait speed using powered robotic exoskeletons after spinal cord injury: a systematic review and correlational study. J Neuroengineering Rehabilitation. 2015;12(1):82. https://doi.org/10.1186/ s12984-015-0074-9.

6. Mirbagheri, M.M., Patel, C., Quiney, K.: Robotic-assisted locomotor training impact on neuromuscular properties and muscle strength in Spinal Cord Injury. Proceedings of the Annual International Conference of the IEEE Engineering in Medicine and Biology Society, EMBS, 4132-4135 (2011). doi: https://doi.org/10.1109/IEMBS.2011.6091026. 
7. Schwartz I, Sajina A, Neeb M, Fisher I, Katz-Luerer M, Meiner Z. Locomotor training using a robotic device in patients with subacute spinal cord injury. Spinal Cord. 2011;49(10):1062-7. https://doi.org/10.1038/sc.2011.59.

8. Schwartz I, Meiner Z. Robotic-assisted gait training in neurological patients: who may benefit? Ann Biomed Eng. 2015;43(5):1260-9. https://doi.org/10. 1007/s10439-015-1283-x 9.

9. Kawashima N, Taguchi D, Nakazawa K, Akai M. Effect of lesion level on the orthotic gait performance in individuals with complete paraplegia. Spinal Cord: the official journal of the International Medical Society of Paraplegia. 2006;44(8):487-94. https://doi.org/10.1038/sj.sc.3101941.

10. Bolliger M, Trepp A, Zörner B, Dietz V. Modulation of spinal reflex by assisted locomotion in humans with chronic complete spinal cord injury. Clin Neurophysiol. 2010;121(12):2152-8. https://doi.org/10.1016/j.clinph.2010.05.018.

11. Donati ARC, Shokur S, Morya E, Campos DSF, Moioli RC, Gitti CM, Augusto PB, Tripodi S, Pires CG, Pereira GA, Brasil FL, Gallo S, Lin AA, Takigami AK, Aratanha MA, Joshi S, Bleuler H, Cheng G, Rudolph A, Nicolelis MAL. Longterm training with a brain-machine Interface-based gait protocol induces partial neurological recovery in paraplegic patients. Sci Rep. 2016;6(April): 30383. https://doi.org/10.1038/srep30383.

12. Aach M, Cruciger O, Sczesny-Kaiser M, Höffken O, Meindl RC, Tegenthoff M, Schwenkreis P, Sankai Y, Schildhauer TA. Voluntary driven exoskeleton as a new tool for rehabilitation in chronic spinal cord injury: a pilot study. Spine J: Official Journal of the North American Spine Society. 2014;14(12):2847-53. https://doi.org/10.1016/j.spinee.2014.03.042.

13. Chisholm AE, Malik RN, Blouin J-S, Borisoff J, Forwell S, Lam T. Feasibility of sensory tongue stimulation combined with task-specific therapy in people with spinal cord injury: a case study. J Neuroengineering and rehabilitation. 2014;11(1):96. https://doi.org/10.1186/1743-0003-11-96

14. NCBI: Meet Toyota Welwalk WW-1000: Robotic System That Can Assist Paralyzed People Walk. 2017;(20017). Available from: http://newsroom. toyota.co.jp/en/detail/mail/15989382.

15. Esquenazi $A$, Talaty $M$, Jayaraman A. Powered exoskeletons for walking assistance in persons with central nervous system injuries: a narrative review. PM\&R. 2017;9(1):46-62.

16. Fleerkotte, B.M., Koopman, B., Buurke, J.H., Asseldonk, E.H.F.V., Kooij, H.V.D., Rietman, J.S.: <the Effect of Impedance Controlled Robotic Gait Training. Pdf>, 1-15 (2014). doi:https://doi.org/10.1186/1743-0003-11-26.

17. Ekkelenkamp, R., Veneman, J., van der Kooij, H.: Lopes: Selective control of gait functions during the gait rehabilitation of cva patients. In: Rehabilitation Robotics, 2005. ICORR 2005. 9th International Conference On, pp. 361-364 (2005). IEEE.

18. Sylos-Labini F, La Scaleia V, D'Avella A, Pisotta I, Tamburella F, Scivoletto G, Molinari M, Wang S, Wang L, van Asseldonk E, van der Kooij $H$, Hoellinger T, Cheron G, Thorsteinsson F, Ilzkovitz M, Gancet J, Hauffe R, Zanov F, Lacquaniti F, Ivanenko YP. EMG patterns during assisted walking in the exoskeleton. Front Hum Neurosci. 2014:8(June):423. https://doi.org/10.3389/ fnhum.2014.00423.

19. Aurich-Schuler T, Grob F, van Hedel HJ, Labruyère R. Can lokomat therapy with children and adolescents be improved? An adaptive clinical pilot trial comparing guidance force, path control, and freed. J NeuroEngineering Rehabilitation. 2017;14(1):76.

20. Arazpour M, Gharib M, Hutchins SW, Bani MA, Curran S, Mousavi ME, Saberi $H$. The influence of trunk extension in using advanced reciprocating gait orthosis on walking in spinal cord injury patients: a pilot study. Prosthetics Orthot Int. 2015;39(4):286-92. https://doi.org/10.1177/0309364614531010.

21. Asselin P, Knezevic S, Kornfeld S, Cirnigliaro C, Agranova-Breyter I, Bauman WA, Spungen AM. Heart rate and oxygen demand of powered exoskeletonassisted walking in persons with paraplegia. J Rehabil Res Dev. 2015;52(2): 147-58. https://doi.org/10.1682/JRRD.2014.02.0060.

22. Kozlowski AJ, Bryce TN, Dijkers MP. Time and effort required by persons with spinal cord injury to learn to use a powered exoskeleton for assisted walking. Topics in Spinal Cord injury rehabilitation. 2015;21(2):110-21. https://doi.org/10.1310/sci2102-110.

23. Contreras-Vidal JL, Bhagat NA, Brantley J, Cruz-Garza JG, He Y, Manley Q, Nakagome S, Nathan K, Tan SH, Zhu F, et al. Powered exoskeletons for bipedal locomotion after spinal cord injury. J Neural Eng. 2016;13(3):031001.

24. Tanabe S, Hirano S, Saitoh E. Wearable power-assist Locomotor (WPAL) for supporting upright walking in persons with paraplegia. NeuroRehabilitation. 2013:33(1):99-106. https://doi.org/10.3233/NRE-130932.

25. Sczesny-Kaiser M, Höffken $O$, Aach $M$, Cruciger $O$, Grasmücke $D$, Meindl R. Schildhauer, T.A., Schwenkreis, P., Tegenthoff, M.: HAL\&R exoskeleton training improves walking parameters and normalizes cortical excitability in primary somatosensory cortex in spinal cord injury patients. Journal of NeuroEngineering and Rehabilitation. 2015;12(1):68. https://doi.org/10.1186/ s12984-015-0058-9.

26. Wall A, Borg J, Palmcrantz S. Clinical application of the hybrid assistive limb (hal) for gait training — a systematic review. Front Syst Neurosci. 2015;9:1-10. doi:10.3389/fnsys.2015.00048.

27. Sale P, Russo EF, Russo M, Masiero S, Piccione F, Calabrò RS, Filoni S. Effects on mobility training and de-adaptations in subjects with spinal cord injury due to a wearable robot: a preliminary report. BMC Neurol. 2016;12:2-9. https://doi.org/10.1186/s12883-016-0536-0.

28. Hartigan C, Kandilakis C, Dalley S, Clausen M, Wilson E, Morrison S, Etheridge S, Farris R. Mobility outcomes following five training sessions with a powered exoskeleton. Topics Spinal Cord Injury Rehabilitation. 2015;21(2): 93-9. https://doi.org/10.1310/sci2102-93.

29. Houldin A, Luttin K, Lam T. Locomotor adaptations and aftereffects to resistance during walking in individuals with spinal cord injury. J Neurophysiol. 2011;106(1):247-58. https://doi.org/10.1152/jn.00753.2010.

30. Lam T, Pauhl K, Ferguson A, Malik RN, Krassioukov A, Eng JJ. Training with robot-applied resistance in people with motor-incomplete spinal cord injury. Pilot Study. 2015;52(1):113-30.

31. Evans N, Hartigan C, Kandilakis C, Pharo E, Clesson I. Acute Cardiorespiratory and metabolic responses during exoskeleton-assisted walking Overground among persons with chronic spinal cord injury. Topics in Spinal Cord Injury Rehabilitation. 2015;21(2):122-32. https://doi.org/10.1310/sci2102-122.

32. Dietz V, Grillner S, Trepp A, Hubli M, Bolliger M. Changes in spinal reflex and locomotor activity after a complete spinal cord injury: a common mechanism. Brain. 2009;132(8):2196-205. https://doi.org/10.1093/brain/awp124.

33. Gordon KE, Wu M, Kahn JH, Schmit BD. Feedback and feedforward locomotor adaptations to ankle-foot load in people with incomplete spinal cord injury. J Neurophysiol. 2010;104(3):1325-38. https://doi.org/10.1152/jn. 00604.2009.

34. Hubli M, Dietz V, Bolliger M. Influence of spinal reflexes on the locomotor pattern after spinal cord injury. Gait Posture. 2011;34(3):409-14. https://doi. org/10.1016/j.gaitpost.2011.06.012.

35. Mirbagheri, M.M., Niu, X., Kindig, M., Varoqui, D.: The effects of locomotor training with a robotic-gait orthosis (Lokomat) on neuromuscular properties in persons with chronic SCl. Proceedings of the Annual International Conference of the IEEE Engineering in Medicine and Biology Society, EMBS, 3854-3857 (2012). doi:https://doi.org/10.1109/EMBC.2012.6346808.

36. Knikou M. Functional reorganization of soleus $\mathrm{H}$-reflex modulation during stepping after robotic-assisted step training in people with complete and incomplete spinal cord injury. Exp Brain Res. 2013;228(3):279-96. https://doi. org/10.1007/s00221-013-3560-y.

37. Smith AC, Mummidisetty CK, Rymer WZ, Knikou M. Locomotor training alters the behavior of flexor reflexes during walking in human spinal cord injury. J Neurophysiol. 2014;112(9):2164-75. https://doi.org/10.1152/jn.00308.2014.

38. Mirbagheri MM, Kindig MW, Niu X. Effects of robotic-locomotor training on stretch reflex function and muscular properties in individuals with spinal cord injury. Clin Neurophysiol. 2015;126(5):997-1006. https://doi.org/10. 1016/j.clinph.2014.09.010. 15334406.

39. Lünenburger L, Bolliger M, Czell D, Müller R, Dietz V. Modulation of locomotor activity in complete spinal cord injury. Exp Brain Res. 2006;174(4): 638-46. https://doi.org/10.1007/s00221-006-0509-4.

40. Banz R, Bolliger M, Colombo G, Dietz V, Lünenburger L. Computerized visual feedback: an adjunct to robotic-assisted gait training. Phys Ther. 2008:88(10): 1135-45. https://doi.org/10.2522/ptj.20070203.

41. Moreh E, Meiner Z, Neeb M, Hiller N, Schwartz I. Spinal decompression sickness presenting as partial brown-sequard syndrome and treated with robotic-assisted body-weight support treadmill training. J Rehabil Med. 2009;41(1):88-9. https://doi.org/10. 2340/16501977-0279

42. Manella KJ, Torres J, Field-Fote EC. Restoration of walking function in an individual with chronic complete (AIS a) spinal cord injury. J Rehabil Med. 2010:42(8):795-8. https://doi.org/10.2340/16501977-0593.

43. Labruyère, R., Hedel, H.J.A.V.: < Strength Training Vs Robot Assisted Gait Training After Incomplete.Pdf>, 1-12 (2014).

44. Niu X, Varoqui D, Kindig M, Mirbagheri MM. Prediction of gait recovery in spinal cord injured individuals trained with robotic gait orthosis. J NeuroEngineering Rehabilitation. 2014;11(1):42. https://doi.org/10.1186/1743-0003-11-42.

45. Gordon KE, Wald MJ, Schnitzer TJ. Effect of parathyroid hormone combined with gait training on bone density and bone architecture in people with 
chronic spinal cord injury. Pm R. 2013;5(8):663-71. https://doi.org/10.1016/j. pmrj.2013.03.032.

46. Varoqui D, Niu X, Mirbagheri MM. Ankle voluntary movement enhancement following robotic-assisted locomotor training in spinal cord injury. J Neuroengineering Rehabilitation. 2014;11(1):46. https://doi.org/10.1186/ 1743-0003-11-46.

47. Hoekstra F, van Nunen MPM, Gerrits KHL, Stolwijk-Swüste JM, Crins MHP, Janssen TWJ. Effect of robotic gait training on cardiorespiratory system in incomplete spinal cord injury. J Rehabil Res Dev. 2014;50(10): 1411-22. https://doi.org/10.1682/JRRD.2012.10.0186.

48. Galen SS, Clarke CJ, Allan DB, Conway BA. A portable gait assessment tool to record temporal gait parameters in SCl. Med Eng Phys. 2011;33(5):626-32. https://doi.org/10.1016/j.medengphy.2011.01.003.

49. Lam T, Pauhl K, Krassioukov A, Eng JJ. Using robot-applied resistance to augment body-weight-supported treadmill training in an individual with incomplete spinal cord injury. Phys Ther. 2011;91(1):143-51. https://doi.org/ 10.2522/ptj.20100026.

50. Fenuta AM, Hicks AL. Metabolic demand and muscle activation during different forms of bodyweight supported locomotion in men with incomplete SCl. Biomed Res Int. 2014;2014 https://doi.org/10.1155/2014/ 632765.

51. Yang A, Asselin P, Knezevic S, Kornfeld S, Spungen A. Assessment of inhospital walking velocity and level of assistance in a powered exoskeleton in persons with spinal cord injury. Topics in Spinal Cord Injury Rehabilitation. 2015;21(2):100-9. https://doi.org/10.1310/sci2102-100.

Submit your next manuscript to BioMed Central and we will help you at every step:

- We accept pre-submission inquiries

- Our selector tool helps you to find the most relevant journal

- We provide round the clock customer support

- Convenient online submission

- Thorough peer review

- Inclusion in PubMed and all major indexing services

- Maximum visibility for your research

Submit your manuscript at www.biomedcentral.com/submit
Biomed Central 